\title{
La docència en Ciència i Tecnologia de la Informació Geogràfica a Catalunya (2006-2009): una aproximació quantitativa
}

\author{
Pere Serra \\ Mireia Pou \\ Xavier Pons \\ Universitat Autònoma de Barcelona. Departament de Geografia \\ pere.serra@uab.cat \\ mireia.pou@uab.cat \\ xavier.pons@uab.cat
}

Recepció: desembre de 2011

Acceptació: febrer de 2012

\section{Resum}

L'article sintetitza els resultats obtinguts en una enquesta realitzada a tots els centres de docència de Catalunya que han impartit estudis superiors o cursos especialitzats o relacionats amb l'àrea de Ciència i Tecnologia de la Informació Geogràfica (CTIG) des de l'any 2006 fins al 2009. L'estudi permet tenir un coneixement raonablement acurat del desenvolupament de l'esmentada disciplina al nostre país gràcies a les 76 respostes obtingudes (el $54 \%$ del total dels enquestats). Els resultats mostren l'elevat nombre d'alumnes involucrats, amb una estimació total de 6.457, així com el seu origen, on l'atracció d'alumnes no catalans queda ben palesa. També cal destacar que el $42 \%$ de les assignatures en estudis superiors amb contingut CTIG s'ha impartit des de departaments de geografia, en llicenciatures molt diverses, programades majoritàriament en el segon i tercer any de llicenciatura i amb una elevada obligatorietat. Pel que fa als continguts, cal destacar la preponderància dels relacionats amb els sistemes d'informació geogràfica seguida de la cartografia $i$, en menor grau, de la teledetecció. En definitiva, el treball mostra un elevat grau d'implantació de la CTIG entre els anys 2006 i 2009, amb una tendència a augmentar dins de l'ensenyament superior de Catalunya.

Paraules clau: enquesta; Ciència i Tecnologia de la Informació Geogràfica (CTIG); docència; SIG; teledetecció; cartografia; fotogrametria.

Resumen. La docencia en Ciencia y Tecnología de la Información Geográfica en Cataluña (2006-2009): una aproximación cuantitativa

El artículo sintetiza los resultados obtenidos en una encuesta realizada a todos los centros de docencia de Cataluña que han impartido estudios superiores o cursos especializados o relacionados con el área de Ciencia y Tecnología de la Información Geográfica (CTIG) desde el año 2006 hasta el 2009. El estudio permite tener un conocimiento razonablemente preciso del desarrollo de la disciplina en Cataluña gracias a las 76 respuestas recibidas (el 54\% del total de encuestas). Los resultados muestran el elevado número de alumnos involucrados, 
con una estimación total de 6.457 , así como su origen, donde la atracción de alumnos no catalanes queda claramente patente. También cabe destacar que el $42 \%$ de las asignaturas en estudios superiores con contenido CTIG se ha impartido desde departamentos de geografía, en licenciaturas muy diversas, programadas mayoritariamente en el segundo y tercer año de licenciatura y con una elevada obligatoriedad. En relación a los contenidos, cabe destacar la preponderancia de los relacionados con los sistemas de información geográfica seguida de la cartografía y, en menor grado, de la teledetección. En definitiva, el trabajo muestra el elevado grado de implantación de la CTIG entre los años 2006 y 2009, con una tendencia a aumentar en el seno de la enseñanza superior en Cataluña.

Palabras clave: encuesta; Ciencia y Tecnología de la Información Geográfica (CTIG); docencia; SIG; teledetección; cartografía; fotogrametría.

Résumé. Enseignement des Sciences et Technologies connexes d'Information Géographique en Catalogne (2006-2009): une approche quantitative

L'article résume les résultats d'une enquête auprès de tous les centres de formation de la Catalogne ont donné l'enseignement supérieur ou des cours spécialisés ou des Sciences et Technologies connexes d'Information Géographique (STIG) de 2006 à 2009. L'étude permet un développement plus approfondi de cette science dans notre pays grâce aux 76 réponses ( $54 \%$ des répondants). Les résultats montrent le nombre élevé d'élèves concernés, avec un total estimé de 6.457 , ainsi que son origine, où l'attraction des étudiants non catalans est évidente. Parmi ces convient également de noter que $42 \%$ des sujets dans l'enseignement supérieur ont donné STIG contenu de départements de géographie, à des degrés très différents, la plupart du temps prévu dans les deuxième et troisième année et avec un haut degré d'obligation. En ce qui concerne le contenu, il y avait une prépondérance du contenu lié aux systèmes d'information géographiques et cartographie suivie par une moindre mesure de la télédétection. En bref, l'étude montre un degré élevé de consolidation du STIG entre 2006 et 2009 avec une tendance à augmenter son poids dans l'enseignement supérieur en Catalogne.

Mots clé: enquête; Science et Technologie de l'Information Géographique (STIG); enseignement; SIG; télédétection; cartographie; photogrammétrie.

\section{Abstract. Teaching Geographic Information Science and Technology in Catalonia (2006- 2009): A quantitative approach}

The article summarizes the results of a survey conducted of all the Catalonian training centers that have given higher education or specialized or related courses in Geographic Information Science and Technology (GIST) from 2006 to 2009. The study provides more thorough knowledge of this discipline in our country thanks to the 76 responses obtained ( $54 \%$ of all respondents). The results show that a large number of students are involved in GIST (an estimated total of 6,457), many of which are of non-Catalonian origin. The results also show that $42 \%$ of the geography departments in higher education institutions have taught GIST content in a wide variety of degree programs, mostly in second and third year compulsory courses. As regards course content, there was a predominance of content related to geographical information systems, followed by cartography and to a smaller degree by remote sensing. The study shows that GIST was widely introduced and increased in importance from 2006 to 2009 in higher education in Catalonia.

Keywords: survey; Geographic Information Science and Technology (GIST); teaching; GIS; remote sensing; cartography; photogrammetry. 


\section{Sumari}

1. Introducció Referències bibliogràfiques

2. Metodologia Annex 1. Estudis de postgrau,

3. Resultats assignatures en estudis superiors i cursos

4. Conclusions especialitzats en CTIG que van contestar

4. Conclusions l'enquesta (per ordre alfabètic)

Agraïments

\section{Introducció}

Des de fa força anys, la Ciència i la Tecnologia de la Informació Geogràfica (CTIG) ha adquirit un paper rellevant en la recerca i en la docència a tot el món. Mostra d'aquest fet és l'elevat nombre de centres educatius i de recerca que empren la CTIG, així com el de publicacions especialitzades i de congressos nacionals i internacionals (Chuvieco et al., 2005), sense oblidar, però, l'ús creixent que se'n fa en administracions i empreses productores o usuàries d'informació geogràfica (AESIG, 2007). Aquest fet mostra la importància de la docència en un àmbit de demanda professional elevada. Al mateix temps, ensenyar aquesta disciplina n'estimula el progrés científic i estableix la terminologia en cada àmbit de la CTIG. En aquest sentit, a Catalunya, la CTIG també té un pes evident, que cal, però, conèixer amb més profunditat. L'objectiu principal d'aquest estudi, encarregat per l'Institut Cartogràfic de Catalunya, és conèixer l'estat de la docència en CTIG a Catalunya, considerant tant els centres privats com públics que imparteixen coneixements a través d'estudis superiors, com també cursos especialitzats. Per tal de delimitar el període temporal, en aquest treball es té en compte aquells estudis vigents durant els anys 2006-2009. Per assolir aquest objectiu, s'ha emprat un qüestionari lliurat a tots els centres docents involucrats en CTIG de Catalunya. Aquest estudi es complementa amb un altre de destinat a la recerca, que serà objecte d'una publicació diferenciada.

Abans d'explicar la metodologia emprada i els resultats obtinguts, cal explicitar una justificació breu de per què en l'estudi s'empra el concepte CTIG i quin és el significat que té. Segons Bosque (1999), es defineix la Ciència de la Informació Geogràfica $(\mathrm{CIG})$ com:

Un cuerpo de conocimiento que pretende el estudio, la investigación y el desarrollo de los conceptos teóricos, los algoritmos matemáticos, los programas informáticos, los instrumentos físicos, las bases de datos, las nuevas formas de uso y la búsqueda de nuevos campos de aplicación, en relación con las tecnologías de la información geográfica. (P. 1)

Com es pot apreciar, la definició no és curta, ja que inclou diversos objectius: estudi, investigació, desenvolupament, etc. En el món anglosaxó, la CIG 
es coneix com Geographic Information Science, GI Science o Geoscience ${ }^{1}$ (Conesa, 2005). El mateix Bosque (1999) esmenta, a continuació, les disciplines implicades en la CIG:

1. Les que tradicionalment han estudiat la IG, com ara la cartografia, la teledetecció, la geodèsia, la topografia o la fotogrametria.

2. Les que ho han fet en format digital, com ara la informàtica o la ciència de la informació.

3. Les que tradicionalment estudien la superfície de la Terra, com ara la geologia, la geofísica, l'oceanografia, l'agronomia, la biologia, les ciències ambientals, la geografia o fins i tot la sociologia i l'antropologia, entre d'altres.

4. Les que estudien la natura del pensament humà i la interacció que estableix amb els ordinadors, com ara la psicologia o la ciència de la cognició.

Pel que fa a Tecnologies de la Informació Geogràfica (TIG), el mateix autor diu: «Nos referimos a los procedimientos desarrollados para reunir y manipular (analizar) la IG, en especial aquella que está expresada en formato digital» (Bosque, 1999: 2). Aquestes tecnologies inclouen les esmentades anteriorment, com ara la topografia, la geodèsia i la cartografia, la fotointerpretació i la fotogrametria o la teledetecció, a més d'altres, com ara els sistemes de navegació basats en satèl.lits (els GNSS (Global Navigation Satellite System), sovint denominats també GPS (Global Positioning System)), i els sistemes d'informació geogràfica (SIG). D'aquí que, en els darrers anys, hagi aparegut o s'hagi emprat força sovint el concepte de «tecnologia SIG» i, més tard, sobretot en el món anglosaxó, el de "ciència SIG» (Conesa, 2005). En aquest sentit, el cas paradigmàtic és el de la revista International Journal of GIS, ja que, des de l'any 1997, va modificar el significat de GIS, de Geographical Information Systems a Geographical Information Science. Els SIG, doncs, són considerats la tecnologia per excelllència de l'aplicació de la CIG. Per tant, l'ús de CTIG en aquest estudi engloba tot l'esmentat anteriorment, la qual cosa ressalta el caràcter multidisciplinari i la integració de processos i tecnologies per obtenir IG.

\section{Metodologia}

\subsection{Fonts principals del qüestionari i motivació de les preguntes}

Les fonts principals emprades per conèixer els centres i les universitats que havien d'aparèixer a l'estudi han estat les següents: la consulta de diverses pàgines i cercadors d'Internet, els resultats d'una enquesta sobre docència en teledetecció realitzada a tot Espanya a través de l'Associació Espanyola de Teledetecció (AET) per a l'any 2008 (AET, 2008), el directori de ¿Quién es quién en teledetección, cartografía y SIG?, de l'AET (2000), els resultats d'un

1. Per a més informació sobre el terme, vegeu Wright et al. (1997). 
estudi realitzat per l'Associació Espanyola de Sistemes d'Informació Geogràfica (AESIG, 2007) i la consulta dels resums dels congressos en CTIG més importants realitzats a Catalunya i a la resta de l'Estat en els darrers anys. Algunes altres enquestes han estat consultades, però, en general, la significació que tenien era molt petita, atès el nombre d'enquestes contestades i/o el biaix del collectiu.

A continuació, s'hi exposen les preguntes formulades i les característiques principals que tenen. Cal esmentar que, per tal de facilitar la tasca dels enquestats, es varen oferir dues vies de resposta, una mitjançant un fitxer PDF editable i l'altra mitjançant una pàgina web (http://llibreblanc.uab.cat). El qüestionari es va adreçar als coordinadors $i$ als directors d'assignatures i cursos especialitzats en CTIG i es va estructurar en tres parts, en funció de la tipologia de docència que s'impartia. Cadascuna d'aquestes tres parts presentava preguntes diverses, algunes de les quals eren coincidents i d'altres no, a causa de l'especificitat que tenien: màsters i diplomatures, assignatures específiques dins de màsters, postgraus, llicenciatures o graus, o bé cursos d'especialització. Així, el qüestionari es va estructurar de la manera següent:

\section{Estudis superiors especialitzats en CTIG}

La primera pregunta d'aquest apartat demanava si, des del centre o l'entitat, es realitzava o s'impartia algun estudi de postgrau especialitzat en CTIG. Un estudi de postgrau és un màster o una diplomatura de postgrau. Es diferencien entre si pel nombre de crèdits i la durada del curs. De les catorze preguntes restants, en destacaven les relacionades amb el nombre d'alumnes i el contingut dels cursos. En relació amb el nombre d'alumnes, se'n va diferenciar tres opcions segons l'origen: els alumnes catalans, els de la resta de l'Estat espanyol i la resta d'estudiants. Amb l'objectiu de fer més facil la resposta, es varen dissenyar uns intervals, molt reduïts (d'1 a 5, de 6 a 10, etc.), que ens permetessin, posteriorment, fer un càlcul estimat del total d'alumnes per curs i per origen. Pel que fa als continguts, es va sol-licitar el percentatge en contingut CTIG respecte al total del curs, el nombre de crèdits ECTS i el programari més emprat.

\section{Estudis superiors relacionats amb la CTIG}

Amb la mateixa estructura que la part anterior, aquesta contenia un grup de preguntes que feien referència a assignatures soltes relacionades amb la CTIG, impartides dins de màsters, graus, llicenciatures o diplomatures. De les catorze preguntes, moltes de les quals eren idèntiques que les de l'apartat anterior, en destacaven les relacionades amb les característiques de la titulació i el tipus d'assignatura. La tipologia de la titulació, és a dir, si era un grau, una llicenciatura, un màster o una diplomatura de postgrau, ens havia de permetre saber si els coneixements CTIG se solen adquirir durant els primers i segons cicles dels estudis universitaris o, per contra, se solen impartir en cursos més especialitzats, com ara els de tercer cicle. Per fer-ne una anàlisi més concreta, es va demanar el curs en el qual s'impartia l'assignatura, així com el tipus d'assignatura de què 
es tractava, si era troncal, obligatòria, optativa, de lliure elecció o un mòdul de màster obligatori o optatiu.

\section{Cursos especialitzats en CTIG}

Per acabar, l'última part, amb onze preguntes, feia referència a aquells cursos d'especialització, de formació continuada, etc., amb continguts en CTIG. La seva estructura tornava a ser molt semblant a la dels apartats anteriors, amb preguntes molt similars, amb l'excepció de la inclusió del centre organitzador del curs i el nivell educatiu requerit per poder-s'hi apuntar.

\subsection{Eines emprades}

Durant la realització de la recerca de les entitats i de les institucions susceptibles de ser incloses a l'estudi, es va creure oportú i molt interessant crear una pàgina web on es pogués consultar la relació d'universitats i/o de centres inclosos en l'estudi. La pàgina web contenia, d'una banda, una explicació breu sobre l'estudi i, de l'altra, els centres als quals s'havia lliurat l'enquesta. D'aquesta manera es pretenia que els centres i les institucions als quals es va enviar el qüestionari poguessin consultar aquesta llista, conèixer els altres destinataris i realitzar-ne qualsevol comentari. Aquesta opció també permetia, tal com es detallava a la carta de presentació de l'estudi, que recomanessin possibles entitats que no hi estiguessin incloses i realitzessin docència en CTIG.

Al llarg dels dos mesos de la primera fase de realització del projecte, es va lliurar un conjunt de cartes a totes les institucions i centres que, al principi, havien de formar part de l'estudi. En una primera fase, es varen enviar les cartes de presentació de l'estudi i de sol-licitud per a la participació, de manera personal $\mathrm{i}$ via correu electrònic, a cada un dels contactes de les entitats i les institucions participants. A les cartes, s'hi exposava els objectius de l'estudi i les qüestions tècniques, per tal de contestar correctament el qüestionari, que, evidentment, hi anava adjunt. En una segona fase, es va considerar la conveniència de lliurar un altre conjunt de cartes, també de manera personal i via correu electrònic, a totes aquelles entitats que estaven cridades a participar-hi i encara no ho havien fet. Un cop enviats els correus electrònics, es va copsar la necessitat de mantenir també un contacte directe per via telefonica, a fi de poder respondre tots aquells dubtes i comentaris que poguessin sorgir. De la mateixa manera, es va usar la via telefonica per recordar a aquelles persones a qui es va creure necessari (per problemes amb el correu electrònic, manca de contacte, etc.) la importància de respondre els qüestionaris de l'estudi. Finalment, voldríem comentar també que es va lliurar un correu electrònic d'agraïment a totes les institucions que varen contestar el qüestionari.

A l'hora de crear l'esmentat qüestionari, es va optar per plantejar una enquesta prou completa que permetés obtenir força dades, però defugint-ne una de més extensa que, tot i permetre un estudi més detallat, podia implicar una participació inferior, ja que és conegut que un qüestionari que requereix un llarg temps de resposta sol ser descartat per la majoria d'implicats. 


\section{Resultats}

El nombre total d'enquestes lliurades a persones coordinadores de docència va ser de 76 , de les quals es van rebre 41 respostes (el 54\% del total) provinents de 29 centres docents i corresponents a 9 estudis de postgrau especialitzats en CTIG (el 100\% del total de Catalunya), 62 assignatures d'estudis superiors (el $61 \%$ del total) i 30 cursos d'especialització (el $83 \%$ del total).

Entre els cursos 2006-2007 i 2008-2009, les estimacions en el nombre d'alumnes (segons els intervals explicats en la introducció) varen donar un total, entre postgraus, assignatures d'estudis superiors i cursos especialitzats, de 6.457 , el $74 \%$ dels quals eren catalans; el $14 \%$, de la resta de l'Estat, i el $12 \%$, d'altres països. Els postgraus tingueren en total 408 alumnes; 4.788, les assignatures, i 1.261, els cursos especialitzats.

\subsection{Estudis superiors especialitzats en $C T I G$}

En el període analitzat, han estat vigents a Catalunya sis màsters propis especialitzats en CTIG, un dels quals era no presencial, i tres diplomes de postgrau, un dels quals era no presencial,. El nombre total d'alumnes estimat, durant el període 2006-2009, dels màsters i dels postgraus analitzats va ser de 408 . Segons l'origen, es va estimar que 185 alumnes eren catalans (el 45,3\% del total), amb una tendència a incrementar-se; 129 eren de la resta de l'Estat espanyol (el 31,6\%), també amb una tendència a augmentar, i 94 eren d'altres orígens, però, en aquest cas, mostraven una disminució progressiva (figura 1).

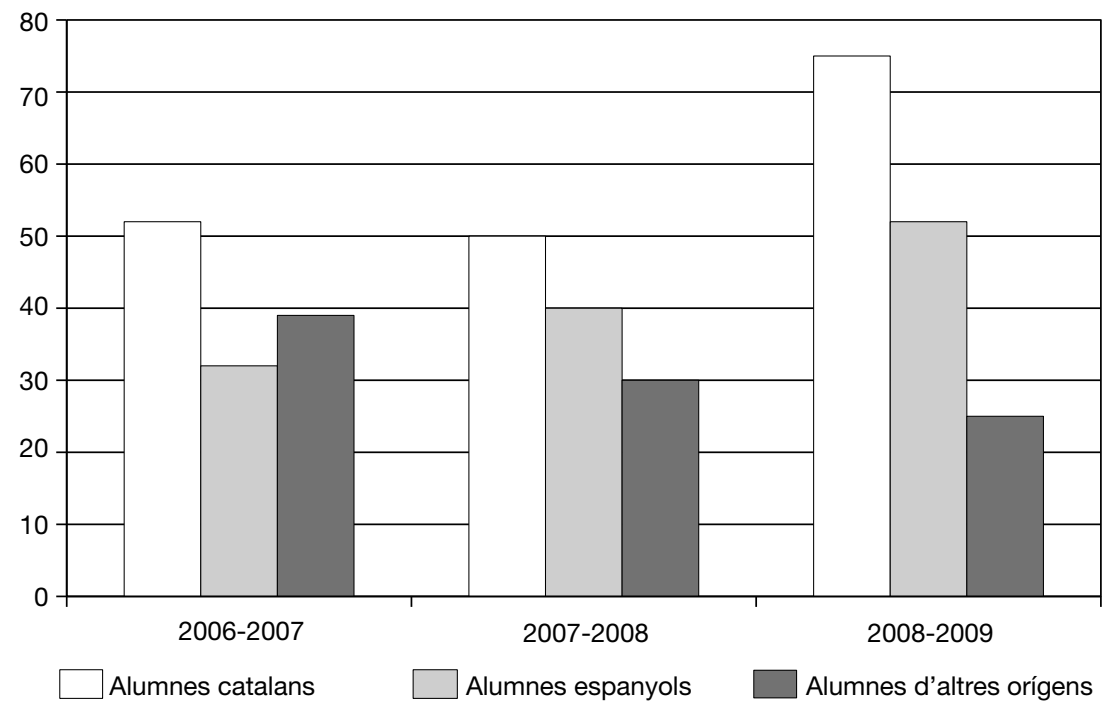

Figura 1. Evolució del nombre d'alumnes de màsters especialitzats en CTIG en el període 2006-2009. 
Pel que fa als continguts, hi havia un màster (CREAF-UAB) que va impartir clarament més teledetecció comparat amb la resta, el 47\%, mentre que un altre impartia més SIG (LIGIT-UAB), el $80 \%$, percentatge, però, ja més proper als tres restants, entre el $65 \%$ i el $70 \%$. La figura 2 mostra aquests resultats, que corresponen als estudis següents: màster en Teledetecció i SIG del Centre de Recerca Ecològica i Aplicacions Forestals (CREAF-UAB), màster en Tecnologies de la Informació Geogràfica del Laboratori d'Informació Geogràfica i Teledetecció (LIGIT-UAB), màster en Producció Cartogràfica i Sistemes d'Informació Geogràfica del Laboratori de Cartografia de la Universitat de Barcelona (PCiSIG-UB), màster en Direcció de Projectes de Sistemes d'Informació Territorial de la Universitat de Girona (DPSIT-UdG), màster Universitari UNIGIS en Gestió de Sistemes d'Informació Geogràfica de la Universitat de Girona (UNIGIS-UdG) i màster en Sistemes d'Informació Geogràfica de la Universitat Politècnica de Catalunya (SIG-UPC).

D'altra banda, segons els crèdits ECTS dels continguts, el percentatge més elevat de tots els màsters va correspondre als continguts pràctics en SIG (el 29\%), seguit dels teòrics en SIG (el 26\%) i dels teòrics en cartografia (el 12\%) (figura 3).

Pel que fa a les diplomatures de postgrau, es va poder comptabilitzar els crèdits del Diploma Universitario de Postgrado Internacional UNIGIS en SIG i del postgrau en SIG per a la Gestió Municipal i Territorial, ja que de la diplomatura de la UdG en Gestió Avançada de SIT no hi havia dades. Igual com en els màsters, la major part dels crèdits va correspondre a SIG pràctics (el 21\%), seguit de SIG teòrics (el 16\%). En relació amb l'ús de programari, en tots els màsters es va emprar ArcGis; en cinc dels quals, MicroStation (de versions dife-

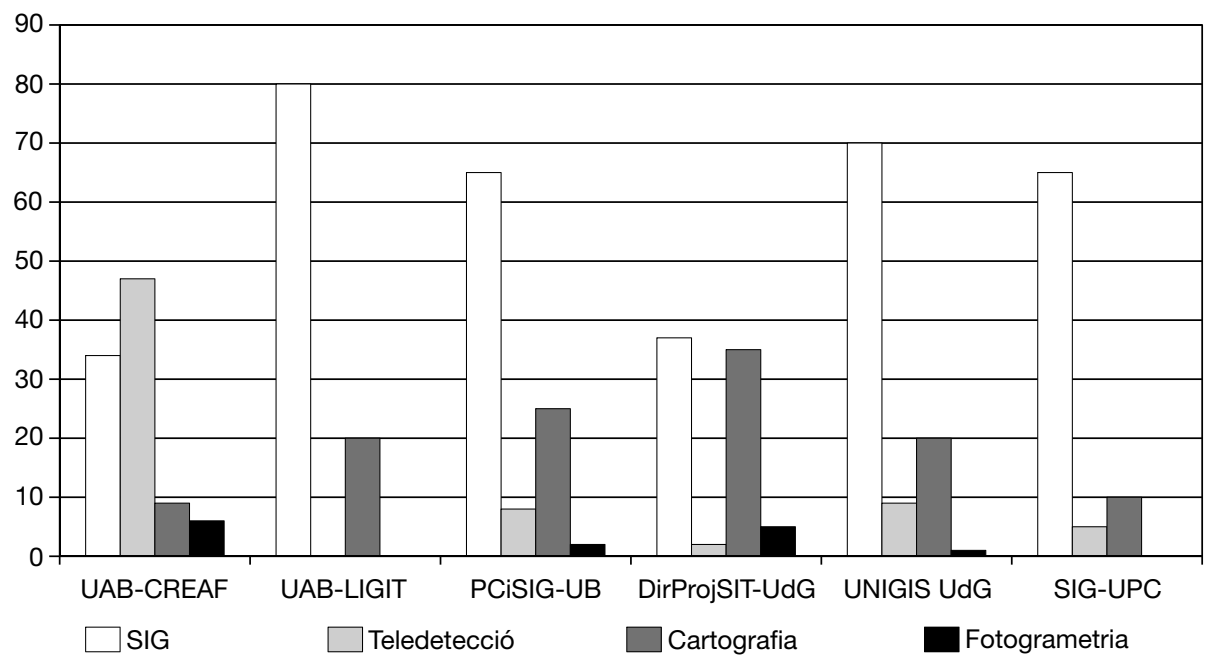

Figura 2. Percentatge de continguts dels màsters especialitzats en CTIG respecte al total del curs. 
rents); mentre que en quatre es va utilitzar MiraMon i gvSIG; en tres, Idrisi i Geomedia; en dos, Envi i Mapinfo, i en un, Ilwis, Surfer i Sextante (figura 4).

\subsection{Estudis superiors amb contingut CTIG}

Hi va haver un total de vint departaments diferents que s'havien implicat en 62 assignatures d'estudis superiors, tant de llicenciatures i graus com de màsters $\mathrm{i}$ doctorat; 38 d'aquestes assignatures (el 61\%) varen correspondre a 19 llicenciatures i graus de diferents universitats, i 24 (el 39\%), a 16 màsters i doctorats. Del total d'assignatures, 26 es varen impartir en departaments de Geografia (el $42 \%$ del total). Sis de les set universitats públiques catalanes varen contestar

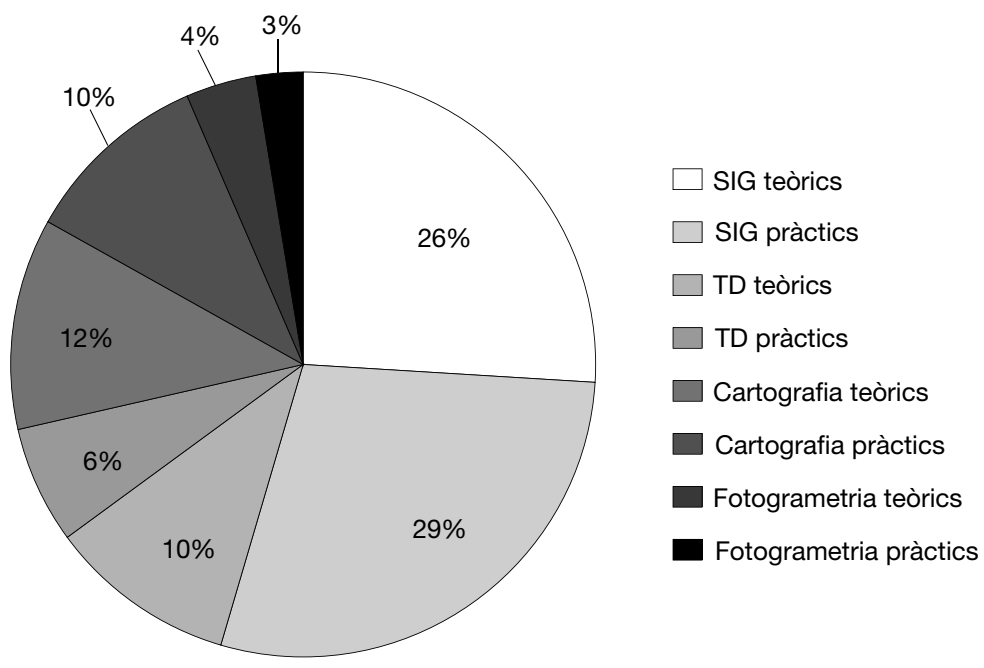

Figura 3. Percentatge del nombre de crèdits ECTS per matèries en els màsters especialitzats en CTIG.

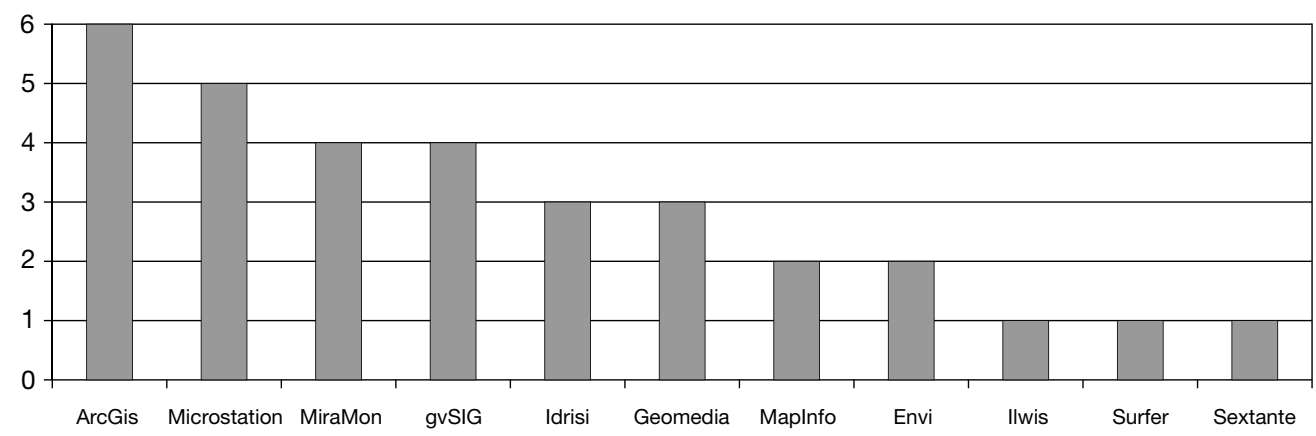

Figura 4. Programari més usat en la docència dels màsters especialitzats en CTIG. 
que havien impartit assignatures relacionades amb la CTIG. Com s'observa a la figura 5, la UB és la universitat que va contestar que havia impartit més assignatures CTIG en estudis superiors, 16 en concret. Posteriorment, apareixen la UPC, amb 14 assignatures, i la UAB, amb 13.

Com s'observa a la figura 6 , hi havia quatre llicenciatures que corresponien a Geografia i quatre més a Ciències Ambientals (CCAA). En el cas de CCAA, cal esmentar que totes les assignatures havien estat impartides per departaments de Geografia excepte en el cas de la Universitat de Vic, on l'assignatura era impartida pel Departament d'Indústries Alimentàries i Medi Ambient. Unes altres llicenciatures implicades eren Geologia, dues d'Enginyeria Tècnica Agrícola i d'Enginyeria Geològica, així com d'Enginyeria de Forests i d'Enginyeria de Camins, Canals i Ports, i també la llicenciatura en Biologia i en Arquitectura Superior. Finalment, cal esmentar que, en el cas de la UOC, les llicenciatures corresponien a Enginyeria Tècnica en Telecomunicació, especialitat en Telemàtica, a Enginyeria Tècnica Informàtica i a Enginyeria Informàtica.

Pel que fa als màsters, majoritàriament oficials, que impartien assignatures soltes en CTIG, eren força diversos: màster en Ecologia Terrestre i Gestió de la Biodiversitat (UAB), màster en Estudis Territorials i de la Població (UAB), màster en Climatologia Aplicada (UB), màster en Gestió i Restauració del Medi Natural (UB), màster en Medi Ambient (UdG), màster en Direcció i Planificació del Turisme (UdG), màster en Gestió de Sòls i Aigües (UdL), màster de Recerca en Sistemes i Productes Forestals (UdL), màster en Gestió Urbanística (UPC), màster en Sostenibilitat (UPC), màster en Planificació Territorial (UPC) i, finalment, màster universitari de recerca en Gestió i Valoració Urbanística (UPC).

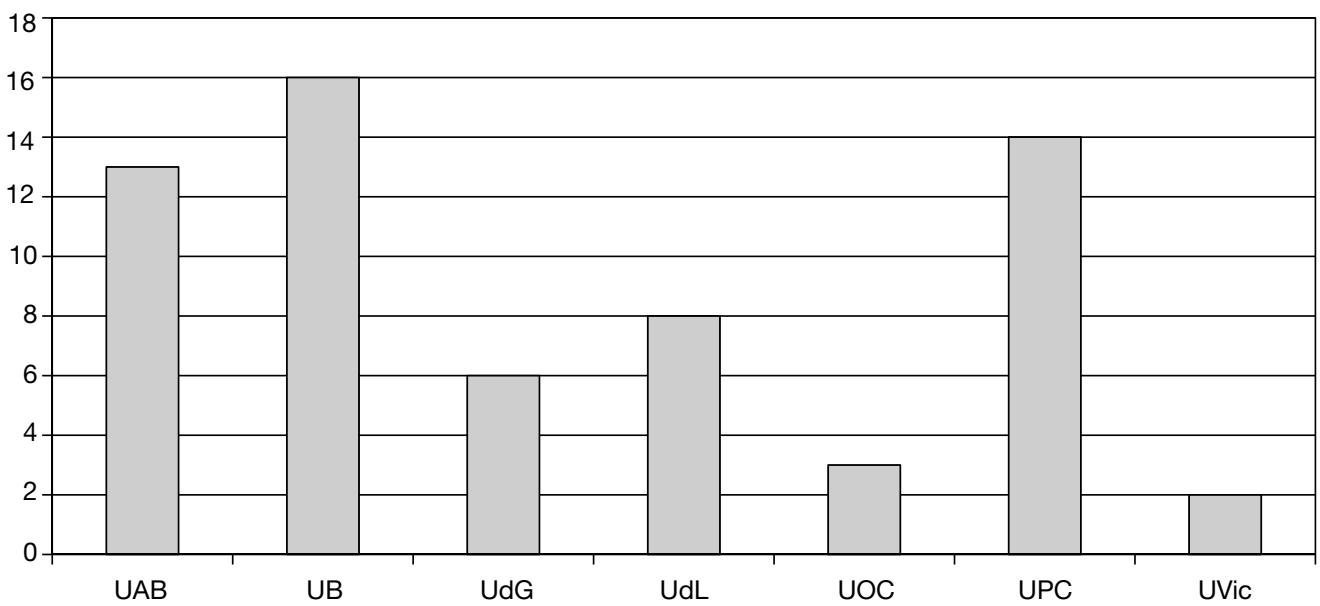

Figura 5. Nombre d'assignatures en estudis superiors especialitzades o amb continguts en CTIG segons les universitats catalanes. 
D'altra banda, la majoria de les assignatures s'havien realitzat entre el segon i el tercer any de llicenciatura o grau. De les 38 assignatures de llicenciatura esmentades (no s'hi comptabilitzen les tres no presencials de la UOC), el 37\% havien estat optatives i el 3\%, de lliure elecció, mentre que el 60\% restant havien estat obligatòries o troncals. Pel que fa als màsters i als doctorats, hi predominava l'optativitat per sobre de l'obligatorietat, ja que 16 assignatures eren optatives, mentre que 8 eren obligatòries.

El nombre total estimat d'alumnes en els anys analitzats ha estat de 4.788, dels quals 3.618 eren catalans (el 76\%); 568, de la resta de l'Estat (el 12\%), i 602, d'altres orígens (el 12\%). Respecte al curs 2006-2007, els resultats mostren 1.441 alumnes, dels quals 1.141 (el 79\%) eren de llicenciatures. D'aquests 1.441 alumnes, 1.140 eren catalans (el 79\% del total); 115 , de la resta de l'Estat (el 8\%), i 186, d'altres orígens (el 13\%). En el curs 2007-2008, el nombre total d'alumnes va ser de 1.637, dels quals 1.192 varen ser de llicenciatures (el 73\%). D'aquests 1.637 alumnes, 1.213 eren catalans (el 74\%); 222, de la resta de l'Estat (el 14\%), i 202, d'altres orígens (el 12\%). Finalment, per al curs 2008-2009, el nombre total d'alumnes va ser de 1.710, dels quals 1.300 varen ser de llicenciatures (el 76\%). D'aquests 1.710 alumnes, 1.265 eren catalans (el 74\%); 231, de la resta de l'Estat (el 13.5\%), i 214, d'altres orígens (el 12,5\%) (figura 7).

A través del percentatge en els continguts de les assignatures, s'observa que en 32 assignatures (el 52\% del total) el contingut havia estat igual o superior al 50\% en SIG (figura 8). A continuació, en 28 assignatures, la cartografia presentava continguts entre el $10 \mathrm{i}$ el 50\% de l'assignatura (el 45\% del total), mentre que la teledetecció ho feia en 21 assignatures (el 34\%). D'altra banda, la fotogrametria presentava un contingut igual a zero en 52 assignatures (el 84\%).

Pel que respecta al nombre de crèdits ECTS dels continguts, el 23\% corresponien a crèdits pràctics en SIG, i el 19\%, a crèdits teòrics. Els següents en importància eren els pràctics (el 15\%) i els teòrics (el 14\%) en cartografia, mentre que els pràctics i els teòrics en teledetecció presentaven el $13 \%$ i el

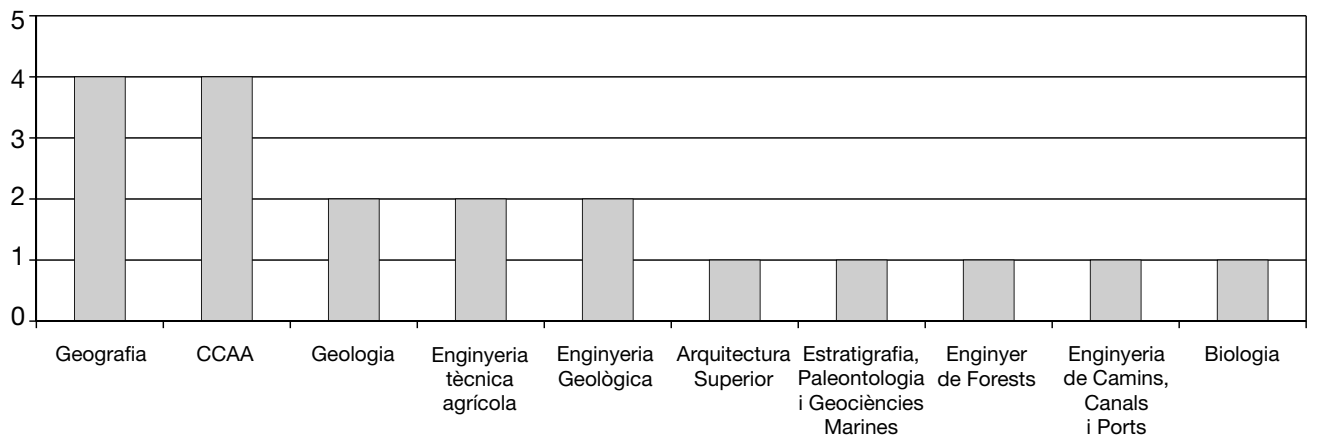

Figura 6. Nombre d'universitats amb llicenciatures que contenen assignatures de CTIG. 


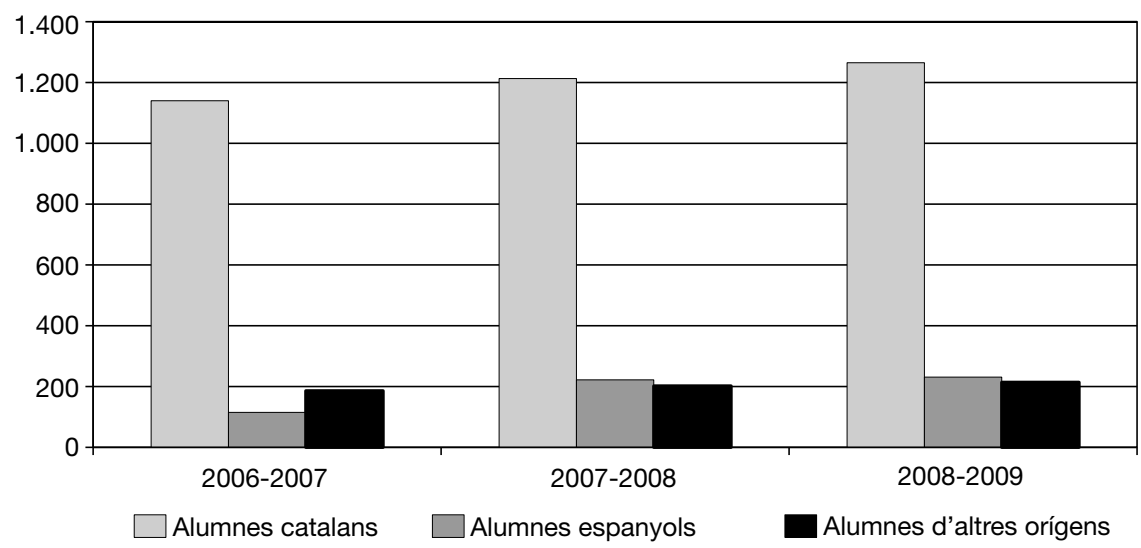

Figura 7. Evolució del nombre d'alumnes d'assignatures especialitzades en CTIG durant el període 2006-2009.

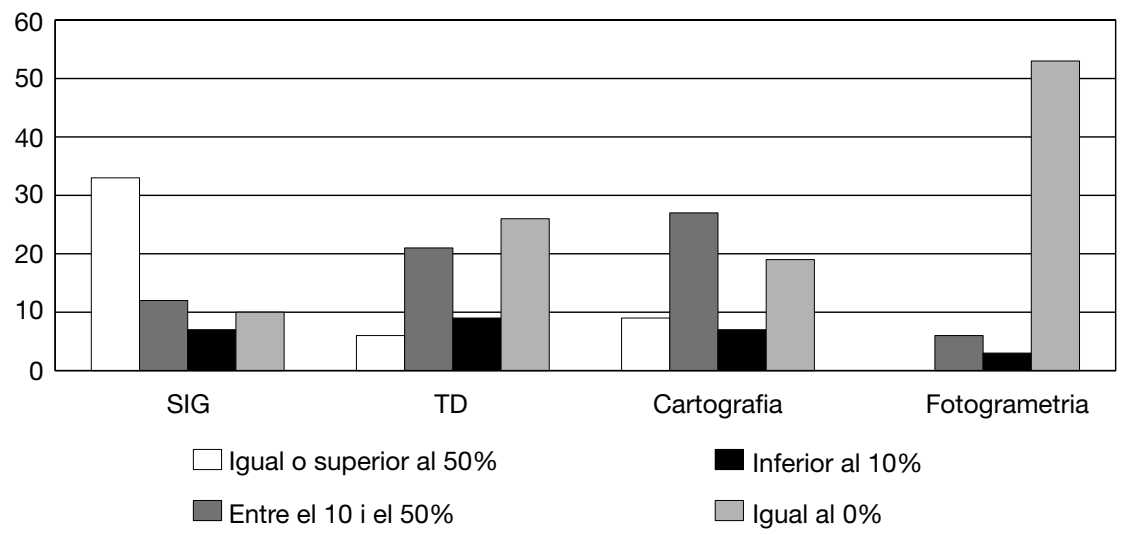

Figura 8. Nombre d'assignatures en estudis superiors segons el percentatge dels continguts en SIG, teledetecció, cartografia i fotogrametria.

$10 \%$, respectivament. Els programes més emprats foren l'ArcGis, amb el 30\%, i el MiraMon, amb el 23\%; l'Idrisi, amb el 14\%, i el gvSIG, amb el 10\% (figura 9).

\subsection{Cursos especialitzats en $C T I G$}

El nombre total de cursos analitzats en l'enquesta ha estat de 30. Els cursos amb una tradició més llarga eren el curs estàndard MiraMon (amb 18 edicions), impartit pel CREAF; el curs de Cartografia Digital amb Microstation, impartit pel Departament de Geologia de la UB, i el Curs d'Especialització en 


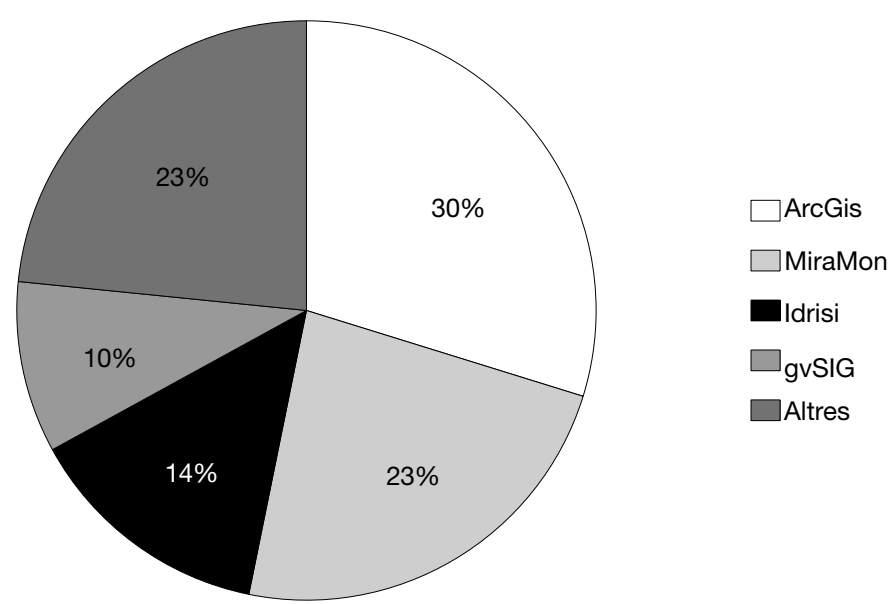

Figura 9. Percentatge del programari més emprat en funció del nombre d'assignatures.

ArcGis 9.1 Aplicat a la Gestió Ambiental, impartit per la Fundació Universitat de Girona: Innovació i Formació - UdG (tots dos amb 12 edicions). Aquesta fundació també va impartir sis cursos més relacionats amb les bases de dades i els SIG. Igualment des de Girona, però impartits per la Càtedra de Geografia i Pensament Territorial, s'organitzaren quatre cursos relacionats amb els sistemes d'informació territorial i un altre d'específic d'elaboració de mapes, mentre que, des de la Facultat de Geografia i Història de la UB, s'organitzà un curs en SIG i GPS.

Els centres que han impartit més cursos especialitzats han estat el LIGIT de la UAB i el CREAF. El LIGIT ha organitzat set cursos relacionats amb productes ESRI (ArcIMS, ArcGis, ArcInfo i ArcObjects), un de creació de Geoserveis OGC amb Programari Lliure i, finalment, un d'Usuari d'AutoCAD Map 3D 2009, mentre que el CREAF ha organitzat, a més de l'esmentat anteriorment, quatre cursos especialitzats en MiraMon (SIG per a Geòlegs, un curs Avançat, un altre d'Anàlisi i un de Navegadors i Servidors de Mapes OGC (Open Geospatial Consortium)). Uns altres cursos destacables varen ser el de la Societat Catalana de Lepidopterologia, que va organitzar un curs de SIG Aplicat a l'Estudi dels Lepidòpters; el de l'ICC, amb un curs titulat Tutorials Tecnologies de la Geoinformació (TGEO), i, finalment, l'organitzat pel Centre de la Propietat Forestal titulat Metabosc, Lifor i MiraMon.

El nombre total d'alumnes dels cursos especialitzats en els tres anys analitzats ha estat de 1.261, dels quals 998 eren catalans (el 79\%); 181, de la resta de l'Estat (el 14\%), i 82, d'altres orígens (el 7\%) (figura 10). El nombre total d'alumnes s'ha anat incrementant cada any, dels 340 del curs 2006-2007 fins als 548 del curs 2008-2009, passant pels 373 del curs 2007-2008. Els alumnes 
catalans dels 340 totals del curs 2006-2007 varen ser 280 (el 82\%), mentre que 39 foren de la resta de l'Estat (el 12\%), i 21, d'altres orígens (el 6\%). Pel que respecta al curs 2007-2008, els 295 alumnes catalans representaren el 87\% dels 373 totals, mentre que els 49 de la resta de l'Estat eren el 15\%, i els d'altres orígens, el 6\%. Finalment, en el curs 2008-2009, els 423 alumnes catalans representaren el $77 \%$ dels 548 totals, mentre que els 93 de la resta de l'Estat foren el $17 \%$, i els 32 d'altres orígens, el $6 \%$. Hi ha hagut, doncs, una tendència a l'increment en el nombre d'alumnes, sobretot a l'últim curs analitzat.

La figura 11 mostra que 23 cursos (el $77 \%$ dels 30 totals) tenien continguts iguals o superiors al 50\% en SIG; cinc cursos, entre el $10 \mathrm{i}$ el 50\%, i en només dos cursos no se n'oferia cap contingut. En relació amb la teledetecció, hi havia 27 cursos que no en tenien cap contingut, mentre que tres tenien entre el 10 i el 50\% del contingut total. Pel que fa a la cartografia, només sis cursos presentaven continguts iguals o superiors al 50\% (el 20\%), mentre que la fotogrametria només era present en dos cursos entre el 10 i el 50\%.

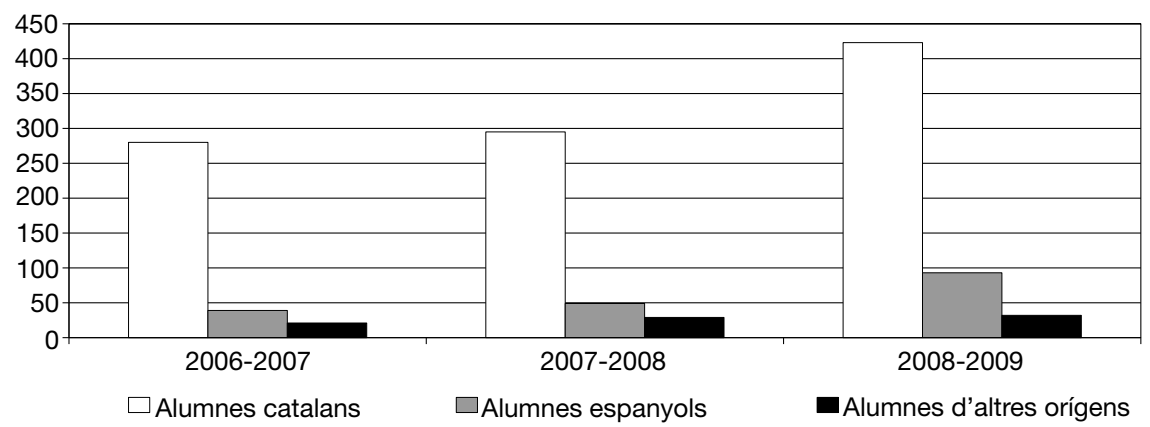

Figura 10. Evolució estimada del nombre d'alumnes de cursos especialitzats en CTIG en el període 2006-2009.

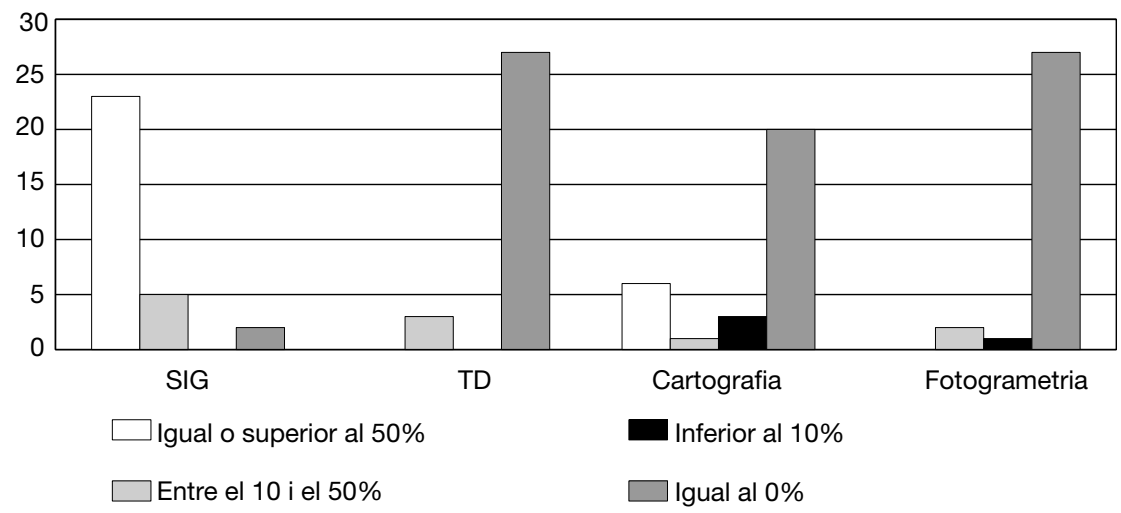

Figura 11. Nombre de cursos d'especialització segons el percentatge dels continguts. 
La majoria de crèdits ECTS corresponien a SIG amb continguts pràctics (el 39\%), mentre que el $20 \%$ corresponia a SIG amb continguts teòrics. A continuació, els percentatges més elevats es donaven en cartografia amb continguts teòrics (el 13\%) i amb continguts pràctics (el 10\%). En relació amb el programari emprat en els cursos especialitzats, el $27 \%$ utilitzava alguna versió d'ArcGis; el 18\%, alguna versió del MiraMon; mentre que el 55\% restant corresponia a uns altres programaris, la qual cosa mostrava l'elevada disgregació d'aquest apartat.

\section{Conclusions}

L'enquesta ha comportat un treball força intensiu, sobretot en l'apartat de seguiment de les respostes, ja que, com sabem, els qüestionaris costen de contestar, generalment per manca de temps. Creiem, però, que, atès el nombre de respostes, el treball resultant és una bona mostra de la situació de la docència en CTIG a Catalunya en el període analitzat.

Els resultats mostren que el nombre d'alumnes que ha estat implicat en formació en CTIG a Catalunya és força considerable (amb una estimació de 6.457) i, el més important, amb una tendència ascendent des del curs 20062007, tant en el cas dels catalans com de la resta de l'Estat espanyol, però no en el cas de la resta d'orígens, amb un lleuger descens, molt probablement a causa de la crisi econòmica mundial. Tal com s'ha esmentat a l'apartat de resultats, més de la meitat dels alumnes de màsters especialitzats eren no catalans, aspecte que reforça l'atracció docent de la CTIG de Catalunya. En el cas dels màsters especialitzats en CTIG, també cal destacar que tots han estat màsters propis, en ressalten els continguts SIG seguits de la cartografia i de la teledetecció $i$ amb un baixíssim contingut en fotogrametria.

En el cas dels estudis superiors amb contingut en CTIG, destaca que el $42 \%$ de les assignatures s'havia impartit en departaments de Geografia. La UB va ser la universitat que n'havia impartit més cursos. Les llicenciatures implicades eren molt diverses, havien estat impartides en el segon i el tercer any de llicenciatura (això vol dir el requeriment d'un cert grau d'experiència per part dels alumnes) $\mathrm{i}$ amb una obligatorietat elevada (el $60 \%$ eren obligatòries o troncals). En relació amb els continguts, hi predominaven els pràctics i teòrics dels SIG, els quals es realitzaven sobretot amb ArcGis i MiraMon. En el cas dels cursos especialitzats, en destaquen els que tenen una llarga tradició (amb més de deu edicions), amb alumnes majoritàriament catalans (el 82\% del total), amb predomini dels continguts SIG i en els quals s'empren els programaris ArcGis i MiraMon.

Així, doncs, les xifres obtingudes en aquest treball mostren la importància de la CTIG a Catalunya, tant en l'ensenyament de màsters com en els estudis universitaris i com va arrelant en moltes altres disciplines a part de la Geografia. En relació amb els resultats obtinguts, creiem que ha estat un bon moment per fer l'enquesta, ja que ens trobem en un temps de canvi propiciat per l'aplicació del Pla Bolonya. En aquest sentit, seria interessant tornar a aplicar l'enquesta 
d'aquí a uns quants anys, per conèixer com pot haver influït aquest nou model en la docència en CTIG de Catalunya, així com realitzar una comparació a nivell estatal o internacional amb els resultats obtinguts, objectiu, però, que ha quedat fora de l'abast d'aquest estudi. Finalment, i encara més lluny de les possibilitats d'aquest estudi però igualment interessant, seria contrastar aquesta oferta i la realització formativa amb la implantació professional.

\section{Agraïments}

Els autors volen agrair a l'Institut Cartogràfic de Catalunya (ICC) el finançament i l'impuls per realitzar aquest estudi; a les entitats participants, la resposta als qüestionaris, cosa que ha fet possible l'elaboració d'aquest document de síntesi, així com als companys i companyes del Grup de Mètodes i Aplicacions en Teledetecció i SIG (GRUMETS) de la Universitat Autònoma de Barcelona, que han contribuït a dissenyar l'estudi en part gràcies al projecte SGR 1511 finançat pel Departament d'Universitats, Recerca i Societat de la Informació de la Generalitat de Catalunya. Xavier Pons és beneficiari d'un ICREA Acadèmia Excellence in Research Grant (2011-2015).

\section{Referències bibliogràfiques}

Asociación Española de Sistemas de Información Geográfica (AESIG) (2007). Estudi del sector TIG a Catalunya 2007 [en línia]. <http://www.actig.cat/aesigcat/ enquesta/AESIG2006v08.pdf> [Consulta: maig 2011].

Asociación Española de Teledetección (2000). ¿Quién es quién en teledetección, cartografia y SIG? [en línia]. <http://telenet.uva.es/qeq/qeq.php> [Consulta: febrer 2011].

- (2008). Estado de la Docencia en Teledetección en España [en línia]. <http://www. aet.org.es/?q=encuesta-docencia-gral1> [Consulta: maig 2011].

Bosque, J. (1999). «La ciencia de la información geográfica y la geografía». VII Encuentro de Geógrafos de América Latina. San Juan de Puerto Rico, 22-26 de marzo, 15 p. CD-ROM.

Chuvieco, Emilio; Bosque, Joaquín; Pons, Xavier; Conesa, Carmelo; Santos, José Miguel; Gutiérrez, Javier; Salado, Ma Jesús; Martín, María Pilar; Riva, Juan de la; Ojeda, José i Prados, Maria José (2005). «¿Son las tecnologías de la información geográfica (TIG) parte del núcleo de la geografía?». Boletín de la Asociación de Geógrafos Españoles, 40, 35-55.

Conesa, C. (2005). «Los Sistemas de Información Geográfica, un tema en auge para el debate: tecnología o ciencia, investigación y aprendizaje, aplicación global o integrada». A: ConesA, C. (ed.). Tecnologias de la Información Geográfica: Territorio y Medio Ambiente. XI Congreso de Métodos Cuantitativos, SIG y Teledetección, Murcia, 20-23 de septiembre de 2004. Servicio de Publicaciones de la Universidad de Murcia, p. 13-52.

Wright, D.J.; Goodchild, M.F. i Proctor, J.D. (1997). «GIS: tool or science? Desmystifying the persistent ambiguity of GIS as "tool" versus "science"». Annals of the Association of American Geographers, 87, 346-362. 


\section{Annex 1. Estudis de postgrau, assignatures en estudis superiors i cursos} especialitzats en CTIG que van contestar l'enquesta (per ordre alfabètic)

\begin{tabular}{|c|c|c|c|}
\hline Codi & Universitat o centre & Nom del curs o assignatura & Titulació \\
\hline \multicolumn{4}{|c|}{ Màsters i postgraus } \\
\hline $\mathrm{D} 001$ & UAB - CREAF & & $\begin{array}{l}\text { Màster en Teledetecció i SIG. } \\
\text { De les imatges de satèl-lit a } \\
\text { la publicació de cartografia a } \\
\text { Internet. }\end{array}$ \\
\hline D002 & UAB - LIGIT & & $\begin{array}{l}\text { Màster en Tecnologies de la } \\
\text { Informació Geogràfica. }\end{array}$ \\
\hline D008 & UB & & $\begin{array}{l}\text { Màster en Producció Cartogràfica } \\
\text { i Sistemes d'Informació } \\
\text { Geogràfica. }\end{array}$ \\
\hline D004 & UdG & & $\begin{array}{l}\text { Màster en Direcció de Projectes } \\
\text { de Sistemes d'Informació } \\
\text { Territorial. }\end{array}$ \\
\hline D004 & UdG & & $\begin{array}{l}\text { Diploma de Postgrau en } \\
\text { Gestió Avançada de Sistemes } \\
\text { d'Informació Territorial. }\end{array}$ \\
\hline D076 & UdL & & $\begin{array}{l}\text { Postgrau en SIG per a la Gestió } \\
\text { Municipal i Territorial. }\end{array}$ \\
\hline D003 & $\begin{array}{l}\text { UNIGIS - Fundació } \\
\text { Universitat de Girona: } \\
\text { Innovació i Formació - UdG }\end{array}$ & & $\begin{array}{l}\text { Màster Universitari UNIGIS en } \\
\text { Gestió de Sistemes d'Informació } \\
\text { Geogràfica. }\end{array}$ \\
\hline D003 & & & $\begin{array}{l}\text { Diploma Universitari de Postgrau } \\
\text { Internacional UNIGIS en SIG. }\end{array}$ \\
\hline D005 & UPC & & $\begin{array}{l}\text { Màster en Sistemes d'Informació } \\
\text { Geogràfica. }\end{array}$ \\
\hline \multicolumn{4}{|c|}{ Assignatures en estudis superiors } \\
\hline D013 & $\begin{array}{l}\text { UAB - Departament de } \\
\text { Biologia Animal, Biologia } \\
\text { Vegetal i Ecologia }\end{array}$ & $\begin{array}{l}\text { Anàlisi i Cartografia de la } \\
\text { Vegetació. }\end{array}$ & Llicenciatura de Biologia. \\
\hline D013 & & $\begin{array}{l}\text { Anàlisi i Cartografia de la } \\
\text { Vegetació. }\end{array}$ & Grau de Biologia. \\
\hline D013 & & Cartografia Ambiental. & $\begin{array}{l}\text { Llicenciatura de Biologia } \\
\text { Ambiental. }\end{array}$ \\
\hline D013 & & $\begin{array}{l}\text { Eines Metodològiques en } \\
\text { Ecologia Terrestre. }\end{array}$ & $\begin{array}{l}\text { Màster en Ecologia Terrestre i } \\
\text { Gestió de la Biodiversitat. }\end{array}$ \\
\hline D013 & & Evolució i Anàlisi del Paisatge. & $\begin{array}{l}\text { Màster en Ecologia Terrestre i } \\
\text { Gestió de la Biodiversitat. }\end{array}$ \\
\hline D010 & $\begin{array}{l}\text { UAB - Departament de } \\
\text { Geografia }\end{array}$ & Introducció a la Teledetecció. & Llicenciatua de Geografia. \\
\hline D010 & & $\begin{array}{l}\text { Sistemes d'Informació } \\
\text { Geogràfica Avançats. }\end{array}$ & Llicenciatura de Geografia. \\
\hline D010 & & $\begin{array}{l}\text { Sistemes d'Informació } \\
\text { Geogràfica. }\end{array}$ & Llicenciatura de Geografia. \\
\hline D010 & & Cartografia i Fotointerpretació. & Llicenciatura de Geografia. \\
\hline D011 & & $\begin{array}{l}\text { SIG i Teledetecció del } \\
\text { Planejament Territorial. }\end{array}$ & $\begin{array}{l}\text { Màster en Estudis Territorials i de } \\
\text { la Població. }\end{array}$ \\
\hline
\end{tabular}




\begin{tabular}{|c|c|c|c|}
\hline Codi & Universitat o centre & Nom del curs o assignatura & Titulació \\
\hline \multicolumn{4}{|c|}{ Assignatures en estudis superiors } \\
\hline D012 & & $\begin{array}{l}\text { Modelització i Anàlisi de la } \\
\text { Informació Geogràfica. }\end{array}$ & $\begin{array}{l}\text { Llicenciatura de Ciències } \\
\text { Ambientals. }\end{array}$ \\
\hline D012 & & Cartografia i Fotointerpretació. & $\begin{array}{l}\text { Llicenciatura de Ciències } \\
\text { Ambientals. }\end{array}$ \\
\hline D016 & $\begin{array}{l}\text { UAB - Institut de Ciència i } \\
\text { Tecnologia Ambientals }\end{array}$ & $\begin{array}{l}\text { Transversal Concepts and } \\
\text { Techniques I i II. }\end{array}$ & $\begin{array}{l}\text { Master Joint European Master in } \\
\text { Environmental Studies (JEMES). }\end{array}$ \\
\hline D042 & $\begin{array}{l}\text { UB - Departament de } \\
\text { Biologia Vegetal }\end{array}$ & $\begin{array}{l}\text { Aplicacions dels Sistemes } \\
\text { d'Informació Geogràfica. }\end{array}$ & $\begin{array}{l}\text { Màster en Gestió i Restauració del } \\
\text { Medi Natural. }\end{array}$ \\
\hline D044 & $\begin{array}{l}\text { UB - Departament de } \\
\text { Geodinàmica i geofísica }\end{array}$ & $\begin{array}{l}\text { Topografia, Fotografia Aèria i } \\
\text { Teledetecció. }\end{array}$ & Llicenciatura de Geologia. \\
\hline D044 & $\begin{array}{l}\text { UB - Departament de } \\
\text { Geodinàmica i geofísica }\end{array}$ & Sensors Remots. & Llicenciatura de Geologia. \\
\hline D040 & $\begin{array}{l}\text { UB - Departament de } \\
\text { Geografia Humana i de } \\
\text { Geografia Física i Anàlisi } \\
\text { Geogràfica Regional }\end{array}$ & $\begin{array}{l}\text { Sistemes d'Informació } \\
\text { Geogràfica. }\end{array}$ & $\begin{array}{l}\text { Llicenciatura de Ciències } \\
\text { Ambientals. }\end{array}$ \\
\hline D046 & & $\begin{array}{l}\text { Tècniques Informàtiques } \\
\text { Aplicades a la Geografia. }\end{array}$ & Llicenciatura de Geografia. \\
\hline D046 & & SIG-II (ARC/INFO i ARCVIEW). & Llicenciatura de Geografia. \\
\hline D046 & & $\begin{array}{l}\text { Sistemes d'Informació } \\
\text { Geogràfica-1. }\end{array}$ & Llicenciatura de Geografia. \\
\hline D046 & & $\begin{array}{l}\text { Tècniques d'Anàlisi } \\
\text { Qualitativa. }\end{array}$ & Llicenciatura de Geografia. \\
\hline D046 & & $\begin{array}{l}\text { Fotointerpretació i Imatges } \\
\text { de Satèl-lit. }\end{array}$ & Llicenciatura de Geografia. \\
\hline D046 & & Cartografia Temàtica. & Llicenciatura de Geografia. \\
\hline D046 & & Cartografia General. & Llicencintura de Geografia. \\
\hline D046 & & Història de la Cartografia. & Llicenciatura de Geografia. \\
\hline D047 & & $\begin{array}{l}\text { Sistemes de Percepció } \\
\text { Remota i Noves Tecnologies. }\end{array}$ & Màster en Climatologia Aplicada. \\
\hline D047 & & $\begin{array}{l}\text { Tècniques de Representació } \\
\text { Espacial. }\end{array}$ & Màster en Climatologia Aplicada. \\
\hline D042 & $\begin{array}{l}\text { UB - Departament } \\
\text { d'Ecologia }\end{array}$ & Aplicacions de la Teledetecció. & $\begin{array}{l}\text { Màster en Gestió i Restauració del } \\
\text { Medi Natural. }\end{array}$ \\
\hline D049 & $\begin{array}{l}\text { UB - Departament } \\
\text { d'Estratigrafia, Paleontologia } \\
\text { i Geociències Marines }\end{array}$ & $\begin{array}{l}\text { Tractament de Dades i } \\
\text { Cartografia. }\end{array}$ & $\begin{array}{l}\text { Estratigrafia, Paleontologia i } \\
\text { Geociències Marines. }\end{array}$ \\
\hline D019 & $\begin{array}{l}\text { UdG - Departament de } \\
\text { Geografia }\end{array}$ & $\begin{array}{l}\text { Geografia Humana Aplicada } \\
\text { (SIG). }\end{array}$ & Llicenciatura de Geografia. \\
\hline D021 & & $\begin{array}{l}\text { Tècniques d'Anàlisi i } \\
\text { Informació Territorial I. }\end{array}$ & $\begin{array}{l}\text { Màster en Direcció i Planificació } \\
\text { del Turisme. }\end{array}$ \\
\hline D022 & & $\begin{array}{l}\text { Anàlisi de la Informació } \\
\text { Geogràfica. }\end{array}$ & $\begin{array}{l}\text { Llicenciatura de Ciències } \\
\text { Ambientals. }\end{array}$ \\
\hline D024 & & $\begin{array}{l}\text { Fonaments de SIG - Mòdul } \\
\text { Instrumental. }\end{array}$ & Màster en Medi Ambient. \\
\hline D024 & & $\begin{array}{l}\text { Aplicacions de SIG i } \\
\text { Teledetecció a l'Anàlisi } \\
\text { Ambiental. }\end{array}$ & Màster en Medi Ambient. \\
\hline
\end{tabular}




\begin{tabular}{|c|c|c|c|}
\hline Codi & Universitat o centre & Nom del curs o assignatura & Titulació \\
\hline \multicolumn{4}{|c|}{ Assignatures en estudis superiors } \\
\hline $\mathrm{D} 020$ & $\begin{array}{l}\text { UdG - Departament } \\
\text { d'Organització, } \\
\text { Gestió Empresarial i } \\
\text { Desenvolupament de } \\
\text { Producte }\end{array}$ & $\begin{array}{l}\text { Expressió Gràfica i } \\
\text { Cartografia. }\end{array}$ & $\begin{array}{l}\text { Enginyeria Tècnica Agrícola, } \\
\text { especialitats Explotacions } \\
\text { Agropecuàries i Indústries } \\
\text { Agràries i Alimentàries. }\end{array}$ \\
\hline D063 & $\begin{array}{l}\text { UdL - Departament de } \\
\text { Geografia i Sociologia }\end{array}$ & $\begin{array}{l}\text { Cartografia Assistida per } \\
\text { Ordinador I. }\end{array}$ & Llicenciatura de Geografia. \\
\hline D063 & & $\begin{array}{l}\text { Cartografia Assistida per } \\
\text { Ordinador II. }\end{array}$ & Llicenciatura de Geografia. \\
\hline D063 & & Cartografia y SIG. & Grau de Geografia. \\
\hline D054b & $\begin{array}{l}\text { UdL - Departament de Medi } \\
\text { Ambient i Ciències del Sòl }\end{array}$ & $\begin{array}{l}\text { Sistemes d'Informació } \\
\text { Geogràfica i Teledetecció. }\end{array}$ & $\begin{array}{l}\text { Enginyeria Agrònoma - Enginyeria } \\
\text { de Forest. }\end{array}$ \\
\hline D055 & & $\begin{array}{l}\text { Sistemes d'Informació } \\
\text { Geogràfica i Teledetecció. }\end{array}$ & Enginyeria de Forests. \\
\hline D056 & & $\begin{array}{l}\text { Sistemes d'Informació i } \\
\text { Avaluació de Sòls. }\end{array}$ & Màster en Gestió de Sòls i Aigües. \\
\hline D055 & $\begin{array}{l}\text { UdL - Departament } \\
\text { d'Enginyeria Agroforestal }\end{array}$ & $\begin{array}{l}\text { Inventari Forestal i } \\
\text { Teledetecció: Revisió de } \\
\text { Tècniques de Detecció } \\
\text { de Canvis en Aplicacions } \\
\text { Forestals. }\end{array}$ & $\begin{array}{l}\text { Màster de Recerca en Sistemes i } \\
\text { Productes Forestals. }\end{array}$ \\
\hline D055 & & Ordenació Forestal Avançada. & Enginyer de Forests. \\
\hline D009 & $\begin{array}{l}\text { UOC - Departament } \\
\text { d'Estudis d'Informàtica, } \\
\text { Multimèdia i } \\
\text { Telecomunicació }\end{array}$ & $\begin{array}{l}\text { Sistemes d'Informació } \\
\text { Geogràfica i Geotelemàtica. }\end{array}$ & $\begin{array}{l}\text { Enginyeria Tècnica en } \\
\text { Telecomunicació, especialitat en } \\
\text { Telemàtica / Grau de Tecnologies } \\
\text { de Telecomunicació. }\end{array}$ \\
\hline D009 & & Treball Final de Carrera. & $\begin{array}{l}\text { Enginyeria Tècnica Informàtica / } \\
\text { Enginyeria de Telecomunicació, } \\
\text { especialitat en Telemàtica. }\end{array}$ \\
\hline D009 & & Projecte Final de Carrera. & Enginyeria Informàtica.. \\
\hline D025 & $\begin{array}{l}\text { UPC - Departament } \\
\text { d'Enginyeria del Terreny, } \\
\text { Cartogràfica i Geofísica }\end{array}$ & Topografia. & $\begin{array}{l}\text { Enginyeria de Camins, } \\
\text { Canals i Ports. }\end{array}$ \\
\hline D027 & & Expressió Gràfica i Topografia. & Enginyeria Geològica. \\
\hline D027 & & $\begin{array}{l}\text { Sistemes d'Informació } \\
\text { Geogràfica. }\end{array}$ & Enginyeria Geològica. \\
\hline D028 & & $\begin{array}{l}\text { Sistemes d'Informació } \\
\text { Geogràfica. }\end{array}$ & $\begin{array}{l}\text { Màster Enginyeria Terreny i } \\
\text { Enginyeria Sísmica. }\end{array}$ \\
\hline D031 & UPC - ETSAB - CPSV & $\begin{array}{l}\text { SIG Aplicats a I'Anàlisi Urbana } \\
\text { i Territorial. }\end{array}$ & $\begin{array}{l}\text { Màster universitari de recerca en } \\
\text { Gestió i Valoració Urbanística. }\end{array}$ \\
\hline D031 & & $\begin{array}{l}\text { TICS Aplicats a l'Anàlisi } \\
\text { Territorial: GIS, Teledetecció, } \\
\text { Modelat 3D i RVU. }\end{array}$ & $\begin{array}{l}\text { Màster universitari de recerca en } \\
\text { Gestió i Valoració Urbanística. }\end{array}$ \\
\hline D039 & & $\begin{array}{l}\text { Sistemes d'Informació } \\
\text { Geogràfica Aplicats a l'Anàlisi } \\
\text { Urbana i Territorial. }\end{array}$ & $\begin{array}{l}\text { Doctorat en Gestió i Valoració } \\
\text { Urbana i Arquitectònica } \\
\text { (CSPV - UPC). }\end{array}$ \\
\hline D039 & & $\begin{array}{l}\text { TICS Aplicades a l'Anàlisi } \\
\text { Territorial: GIS 3D, } \\
\text { Teledetecció, Modelat 3D i } \\
\text { Realitat Virtual Urbana. }\end{array}$ & $\begin{array}{l}\text { Doctorat en Gestió i Valoració } \\
\text { Urbana i Arquitectònica } \\
\text { (CSPV - UPC). }\end{array}$ \\
\hline
\end{tabular}




\begin{tabular}{|c|c|c|c|}
\hline Codi & Universitat o centre & Nom del curs $\mathrm{o}$ assignatura & Titulació \\
\hline \multicolumn{4}{|c|}{ Assignatures en estudis superiors } \\
\hline D031 & $\begin{array}{l}\text { UPC - ETSAB - } \\
\text { Departament de } \\
\text { Construccions } \\
\text { Arquitectòniques }\end{array}$ & $\begin{array}{l}\text { Estudis Urbans amb } \\
\text { Tecnologia Informàtica SIG } \\
\text { (des de } 1994 \text { optativa). }\end{array}$ & $\begin{array}{l}\text { Llicenciatura en Arquitectura } \\
\text { Superior. }\end{array}$ \\
\hline D034 & $\begin{array}{l}\text { UPC - Institut de } \\
\text { Sostenibilitat de la UPC }\end{array}$ & Recursos Naturals. & Màster en Sostenibilitat. \\
\hline D034 & & Diagnosi i Anàlisi Territorial. & Màster en Sostenibilitat. \\
\hline D037 & $\begin{array}{l}\text { UPC, Fundació Politècnica } \\
\text { de Catalunya }\end{array}$ & SIG. Estudis Territorials. & Màster en Planificació Territorial. \\
\hline D037 & & $\begin{array}{l}\text { SIG i Mètodes d'Anàlisi } \\
\text { Territorial. }\end{array}$ & Màster en Gestió Urbanística. \\
\hline D037 & & SIG: Estudis Territorials. & Màster en Gestió Urbanística. \\
\hline D066 & $\begin{array}{l}\text { UVic - Departament } \\
\text { d'Indústries Alimentàries i } \\
\text { Medi Ambient }\end{array}$ & $\begin{array}{l}\text { Sistemes d'Informació } \\
\text { Geogràfica. }\end{array}$ & $\begin{array}{l}\text { Llicenciatura de Ciències } \\
\text { Ambientals. }\end{array}$ \\
\hline D066 & & $\begin{array}{l}\text { Ampliació i Aplicacions } \\
\text { dels Sistemes d'Informació } \\
\text { Geogràfics. }\end{array}$ & $\begin{array}{l}\text { Llicenciatura de Ciències } \\
\text { Ambientals. }\end{array}$ \\
\hline \multicolumn{4}{|c|}{ Cursos especialitzats } \\
\hline D086 & $\begin{array}{l}\text { Centre de la Propietat } \\
\text { Forestal (CPF) }\end{array}$ & $\begin{array}{l}\text { Curs de Metabosc, } \\
\text { Lifor i MiraMon. }\end{array}$ & \\
\hline D070 & $\begin{array}{l}\text { Centre de Recerca } \\
\text { Ecològica i Aplicacions } \\
\text { Forestals (CREAF) }\end{array}$ & $\begin{array}{l}\text { Sistema d'Informació } \\
\text { Geogràfica (SIG - GIS) } \\
\text { MiraMon per a Geòlegs. }\end{array}$ & \\
\hline D070 & & Curs Estàndard MiraMon. & \\
\hline D070 & & Curs Avançat MiraMon. & \\
\hline D070 & & Curs Anàlisi MiraMon. & \\
\hline D070 & & $\begin{array}{l}\text { Curs de Navegadors i } \\
\text { Servidors de Mapes OGC de } \\
\text { MiraMon. }\end{array}$ & \\
\hline D001 & & $\begin{array}{l}\text { Formació Avançada en SIG i } \\
\text { Teledetecció. }\end{array}$ & \\
\hline D003 & $\begin{array}{l}\text { Fundació Universitat de } \\
\text { Girona: Innovació i Formació } \\
\text { - UdG }\end{array}$ & $\begin{array}{l}\text { Curs d'Especialització en } \\
\text { Programació d'Aplicacions } \\
\text { SIG. }\end{array}$ & \\
\hline D003 & & $\begin{array}{l}\text { Curs d'Especialització en } \\
\text { Bases de Dades Espacials. }\end{array}$ & \\
\hline D003 & & $\begin{array}{l}\text { Curs d’Especialització en } \\
\text { Gestió de Projectes SIG. }\end{array}$ & \\
\hline D003 & & $\begin{array}{l}\text { Curs d'Especialització en } \\
\text { SIG i Avaluació d'Impacte } \\
\text { Ambiental. }\end{array}$ & \\
\hline D003 & & $\begin{array}{l}\text { Curs d'Especialització en SIG } \\
\text { i Salut. }\end{array}$ & \\
\hline D003 & & $\begin{array}{l}\text { Curs d'Especialització en } \\
\text { Programari Lliure Aplicat } \\
\text { als SIG. }\end{array}$ & \\
\hline D075 & & $\begin{array}{l}\text { Curs d'Especialització en } \\
\text { ArcGis } 9.1 \text { Aplicat a la Gestió } \\
\text { Ambiental. }\end{array}$ & \\
\hline
\end{tabular}




\begin{tabular}{|c|c|c|}
\hline Codi & Universitat o centre & Nom del curs o assignatura \\
\hline \multicolumn{3}{|c|}{ Cursos especialitzats } \\
\hline D083 & $\begin{array}{l}\text { Institut Cartogràfic de } \\
\text { Catalunya (ICC) }\end{array}$ & $\begin{array}{l}\text { Tutorials Tecnologies de la } \\
\text { Geoinformació: TGEO. }\end{array}$ \\
\hline D079 & $\begin{array}{l}\text { Societat Catalana de } \\
\text { Lepidopterologia }\end{array}$ & $\begin{array}{l}\text { SIG Aplicat a l'Estudi dels } \\
\text { Lepidòpters. }\end{array}$ \\
\hline D002 & $\begin{array}{l}\text { UAB - Laboratori } \\
\text { d'Informació Geogràfica i de } \\
\text { Teledetecció (LIGIT) }\end{array}$ & Curs d'Usuari d'ArcIMS. \\
\hline D002 & & $\begin{array}{l}\text { Curs d'Usuari Avançat } \\
\text { d'ArcGIS 9.x (Arclnfo) - Anàlisi } \\
\text { Espacial. }\end{array}$ \\
\hline D002 & & $\begin{array}{l}\text { Curs d'Usuari d'ArcGIS 9.x } \\
\text { (ArcView). }\end{array}$ \\
\hline D002 & & $\begin{array}{l}\text { Curs d'Administració de } \\
\text { Geobases de Dades amb } \\
\text { ArcGIS 9.x (Arclnfo). }\end{array}$ \\
\hline D002 & & $\begin{array}{l}\text { Curs de Creació de } \\
\text { Geoserveis OGC amb } \\
\text { Programari Lliure. }\end{array}$ \\
\hline D002 & & $\begin{array}{l}\text { Curs d'Usuari d'AutoCAD Map } \\
\text { 3D } 2009 .\end{array}$ \\
\hline D002 & & $\begin{array}{l}\text { Curs de Programació SIG amb } \\
\text { ArcObjects i VBA a ArcGIS } \\
\text { 9.x. }\end{array}$ \\
\hline D008 & $\begin{array}{l}\text { UB - Facultat de Geografia } \\
\text { i Història }\end{array}$ & $\begin{array}{l}\text { Sistemes d'Informació } \\
\text { Geogràfica i GPS. }\end{array}$ \\
\hline D044 & UB - Facultat de Geologia & $\begin{array}{l}\text { Cartografia Digital amb } \\
\text { Microstation. }\end{array}$ \\
\hline D004 & $\begin{array}{l}\text { UdG - Càtedra de Geografia } \\
\text { i Pensament Territorial }\end{array}$ & Informació Territorial. \\
\hline D004 & & $\begin{array}{l}\text { Tecnologia de Sistemes } \\
\text { d'Informació Territorial. }\end{array}$ \\
\hline D004 & & $\begin{array}{l}\text { Models de Dades i de } \\
\text { Representació. }\end{array}$ \\
\hline D004 & & $\begin{array}{l}\text { Anàlisi amb Sistemes } \\
\text { d'Informació Territorial. }\end{array}$ \\
\hline D019 & & $\begin{array}{l}\text { Aprèn a Elaborar Mapes per a } \\
\text { II.lustrar els Teus Treballs. }\end{array}$ \\
\hline
\end{tabular}

